\title{
Interactions Around a Contextually Embedded System
}

\author{
Eva Hornecker \\ The Mobiquitous Lab, Dept. of CIS, University of Strathclyde, Glasgow G11XH, UK \\ Eva.Hornecker@cis.strath.ac.uk
}

\begin{abstract}
This paper discusses observations of visitor interactions around a museum installation. It focuses on how the physical setup and shape of two variants of the installation, a telescope-like viewer and a barrier-free screen, shaped visitor experiences and interactions around and with the system. The analysis investigates contextual embedding, highlighting how to design for indexicality (that is: enabling users to do the 'indexing' between a system and aspects of the environment it relates to), and examines how the two system variants affected people's ability to share the experience and negotiate use.
\end{abstract}

\section{Author Keywords}

Shareability, co-experience, museum, interactivity, context, tangible, embedded, CSCW, indexality

\section{INTRODUCTION}

Museum installations are moving away from touch screen information terminals, giving HCI and Interaction Design researchers opportunity to investigate novel technologies and interaction styles [7, 14, 19, 20,21]. These studies have highlighted the importance of supporting groups of visitors. But how to design for shareability [13] or co-experience [3] is of much wider relevance. The study of a museum installation presented here pursues these research agendas, aiming to understand how different technologies and designs shape how people react to and interact with them, and in particular how these support a sharing of experience.

This research embraces an extended perspective on tangible interaction [9, 12], highlighting how tangible systems are physically embedded in real space and thus situated in social and physical contexts [8], how their physical design can provide 'embodied facilitation' [12] and support social interaction [9, 13, 21]. Here, 'embedded interaction' is used in a different sense to the technical view of embedded computing, and refers to systems that are physically embedded, contextualized and integrated into a meaningful spatial setting. Physical contextualization (cf. [20]) means

.To appear in Proceedings of TEI'2010, Boston, MA ACM 2010 that the interface cannot be analyzed without reference to its setting, as interactions tend to index into these surroundings and take place around the interface while referring to it. The analysis thus stands in the tradition described by Fernaeus et al [9], having an action-centric focus, focusing on interaction in context and around the system and on tangibles as resources for social action.

\section{The Museum of Natural History in Berlin}

The Museum of Natural History in Berlin [17] is one of the world's largest natural history museums. It is famous for the display of gigantic skeletons of Jurassic dinosaurs and Archaeopteryx, the first bird. After two years of renovating and redesigning four major exhibition halls, the museum reopened in July 2007, and drew 250.000 visitors within the first 12 weeks. Typical visitors are families, school groups, and adults interested in nature and geology. The renovated wings feature several interactive installations commissioned and developed by the German media design company ART+COM [2], most prominently media-augmented telescopes called Jurascopes, and an interactive multi-touch table installation about evolution. Furthermore, there are numerous 'dynamic legends' throughout - horizontal information panels with texts and diagrams where visitors can choose images, films and animations on related themes running on integrated screens. This paper focuses on the Jurascopes, developed by ART+COM and the WALL AG.

When visitors enter the museum's large entrance hall, the sight of seven huge dinosaur skeletons immediately enthralls them. The Jurascopes stand in this hall and are designed to create a link between the original skeletons and the virtual reconstructions and 3D animations familar from TV. They show a combination of photos and animations. Looking through a Jurascope, visitors at first see a photo of the skeletons in the hall. By turning it on its base, they select a dinosaur. This starts the animation. Inner organs appear; muscles and skin grow. Then the background of the hall is replaced with a view of a natural environment, where the animal starts moving, feeding and hunting. Sounds from the environment and animals can be heard. Sometimes the animal seems to notice it is being watched, coming closer to glance at the observer or threaten them. Each sequence lasts about 30 seconds. Then the dinosaur moves into its original position, freezes and 'skins down' to the skeleton.

Two sets of Jurascopes are positioned in diagonally opposite corners. They are arranged in a line, some with steps to accommodate visitors of different heights. To provide a barrier-free version for wheelchair users and 


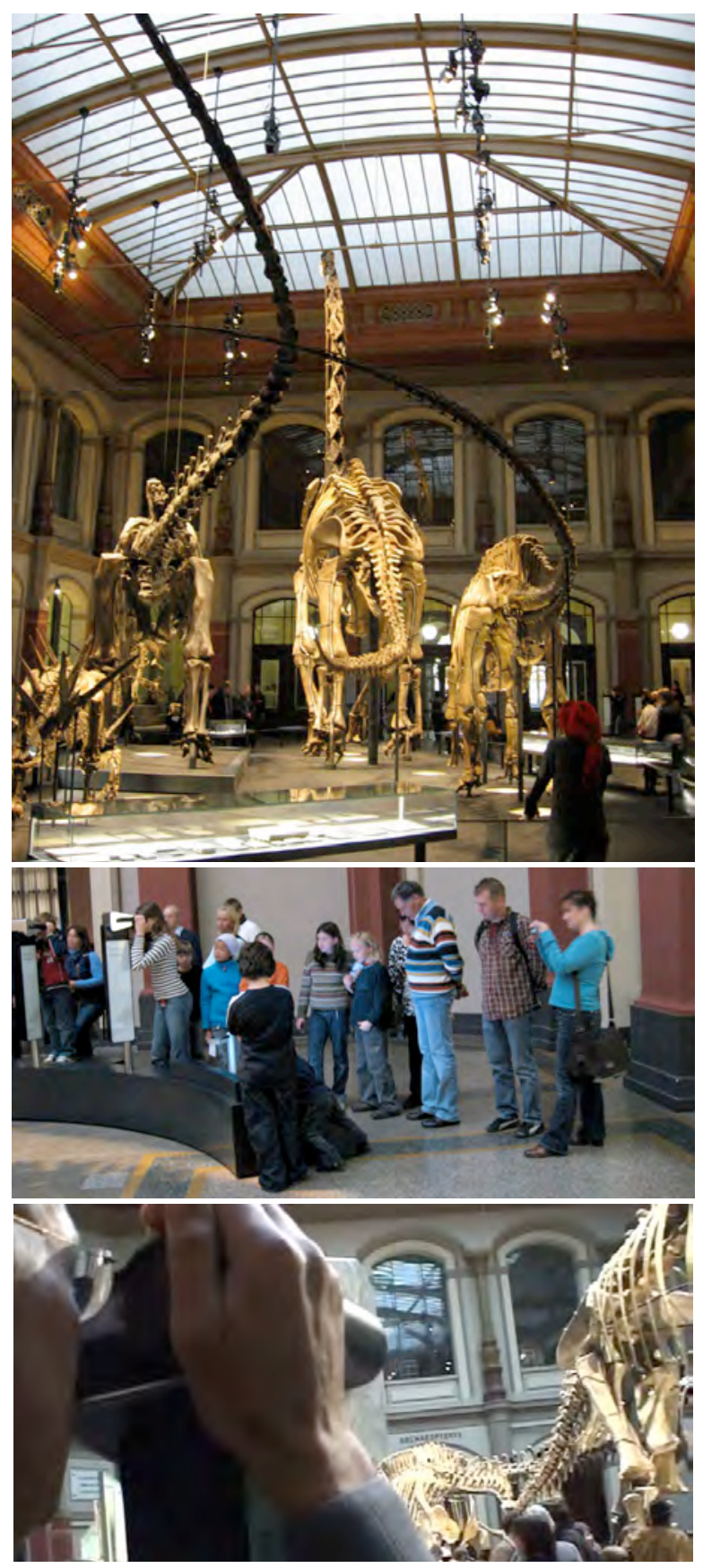

Figure 1. From top to bottom: (a) The majestic dinosaur skeletons in the main hall are set up using their tails as counterbalance, in line with new scientific theories. (b) The Jurascope installation is located in a corner with a screen towards its right side. (c) A visitor looks through a Tele-Jurascope at the dinosaurs.

children, a large screen is embedded at an angle into the floor. Here, dinosaurs are selected by turning a large lever at the side of the screen. The screens have come to play a much bigger role than expected, attracting crowds of viewers. In the remainder of the paper, the two variations of the installation are referred to as Tele-Jurascopes and as screens or together as Jurascopes.

The Jurascopes are interesting as object of analysis for several reasons. The provision of two alternative ways of viewing the same content enables us to compare differences in interaction patterns and user experience that result from the physical setup and interaction mechanisms. Nevertheless, tele-jurascopes and screens contextualize content in similar ways by being in the same space as the skeletons and carefully aligned with them. This differs from the 'tree of life' table installation in the same museum, which provides decontextualized information. A user study [11] found that visitors here engaged mainly in how-to conversations, different from the types of conversations and interactions elsewhere in the museum. Observation revealed that the Jurascope, despite of limited interactivity and range of content, generated rich interactions around it.

\section{Study Approach and Data Collection}

The study followed a rapid ethnography approach, drawing upon principles of ethnography and interaction analysis $[4$, 15], starting from open-ended observation and iteratively evolving issues for detailed analysis. This included other exhibits and halls to get a sense of how the installations integrated into the museum, enabling comparisons between typical activities and conversations in the museum.

Natural history museums, in terms of their audience and 'code of conduct' are very similar to science and technology museums, filled with people chatting, children running around, bustle, noise and activity., Participant observations were conducted over seven days. Visitors were informed at the ticket desk about the study. The researcher walked around and for focused observations stood or sat close to exhibits, taking notes of interactions and conversations. Supplementing notes, a photo documentary was collected, supporting recollection of events, and enabling further analysis, e.g. of patterns of visitor positioning and postures.

In addition, five groups were recruited to be shadowed (accompanied) during their entire visit (see also [11]). These included families with children, groups of young adults, and seniors with adult children. All events occurring around the installations were recorded, as were a few additional sequences at other areas in the museum. Visits lasted between one and three hours. The study resulted in a total of 90 minutes of video material from the Jurascopes that have been transcribed and analyzed. This data is somewhat fragmented, due to overall noise levels and to regulations protecting privacy in public spaces (the video tends to picture only the screen and people's hands or back of heads avoiding faces other than the volunteers).
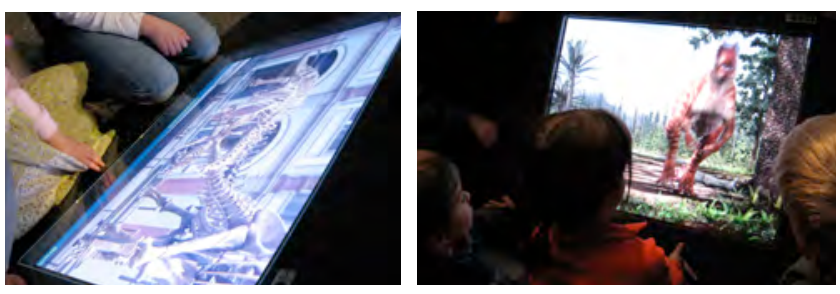

Figure 2. Children at the screen, seeing the skeletons in the museum and an animated film of Allosaurus in threatening pose. 

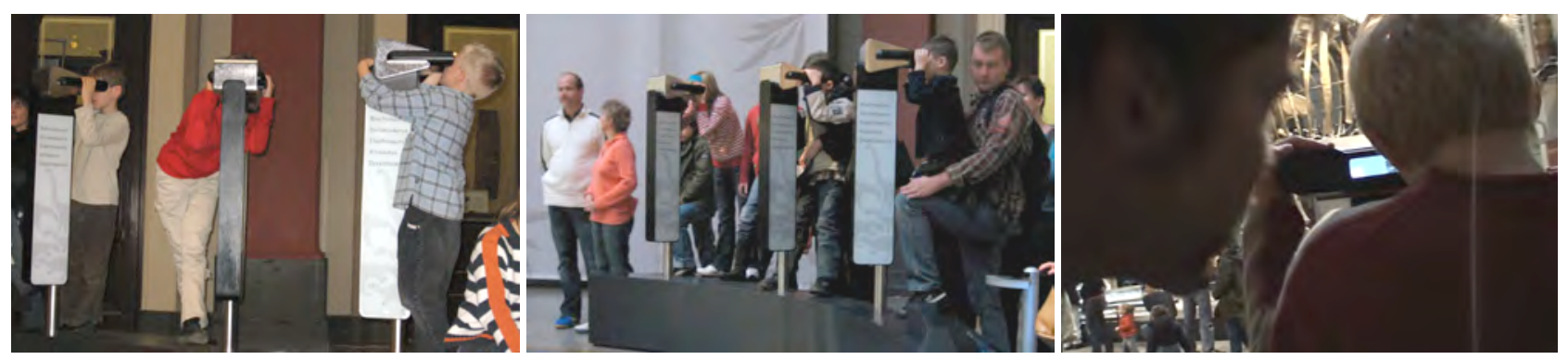

Figure 3. An immersive, but solitary experience at the Tele-Jurascope. Right: A young man tries to get a preview of what it offers. He then turns to his friends in the queue and tells: 'You see the inner facade of the building, oh well, not now, now you see a forest'.

\section{ANALYSIS}

The following sections will look at several of the factors contributing to the installations' success and at the influence of form factors on the user experience. TeleJurascopes and screens differ noticeably with regards to the (social) interactions around the system, and the role of the mechanism for selecting a dinosaur. Both system variants are successful examples of how to establish "clearer links between interactives and the original (art)works" [19] through contextual embedding. The animations also contribute to the success of the installation, and appeal to both children and adults through their diversity and humor.

\section{Different Types of Experience}

The form factors and interaction mechanisms of the telescope-like Jurascopes and the screens each resulted in a very different type of user experience, along with contrasting interactions evolving around the installations.

The Tele-Jurascope provides an immersive experience. Some visitors described it as more direct and 'exciting' than the screens, 'you are more inside the story, and imagine what it would be like if they would run around nowadays'. The viewfinder blocks out the environment (figure 1c). The initial scene shows an empty hall with only the exhibits, and the viewer then seems to observe the dinosaurs from a short distance. The encounter seems quite real, and this is reflected in how people sometimes hissed through their teeth, cringed and pulled back from the viewfinder when a dinosaur 'noticed' the observer, inspecting or threatening them by coming closer and roaring. Visitors reported that the audio sometimes made the telescope vibrate, increasing the intensity of the experience, and they often (falsely) thought they saw a stereoscopic 3D image. On the screen the animations are less immersive, and visitors know they see 'just a movie'. Quite often, children would playfully pretend to challenge the dinosaurs, telling them 'bite me'.
The Tele-Jurascopes' immersiveness comes at a price. They are designed for one person to look through. Being virtually alone adds to the feeling of a direct and personal experience. It also means it is difficult to share. Sometimes, people in the queue tried to figure out what was coming up from the limited cues available (figure $3 \mathrm{c}$ ). Conversations between viewer and queue tended to be disconnected.

(1) A young boy looks through the viewer and talks to a young girl behind him: 'He has the leg of another one'. There are 12 seconds of silence, then the girl asks: 'What does he do now?' The boy does not answer, and 2 seconds later a parent calls him away.

(2) A young woman watches silently for about 20 seconds, while her friends in the queue discuss a video they saw on the dynamic legends. At some point she says: 'they have weird heads' but her friends continue discussing, and do not react to her.

In the first vignette there is an attempt from both sides at sharing and at conversation, but neither succeeds. In vignette 2 the woman seems to be talking to herself, she does not explain what she meant, and her friends ignore the statement. Not having seen the animation, it would be hard for them to reply in a meaningful way.

The difficulty of sharing especially affected the ability of adult caregivers to facilitate children's experience. Parentchild interaction did not adhere to typical patterns of family conversation in museums, where parents pose questions, point out interesting things and answer questions, guiding children's thinking and attention while looking at objects [16]. Most talk related to how to use it ('you need to look at one very long'). Educational conversation or scaffolding of interaction relies on being able to see what the child is doing. Sometimes children jerked the Tele-Jurascope around very quickly, and were thus unlikely to ever watch more then the beginning of an animation. Adult caregivers often did not notice this and the child was not assisted.
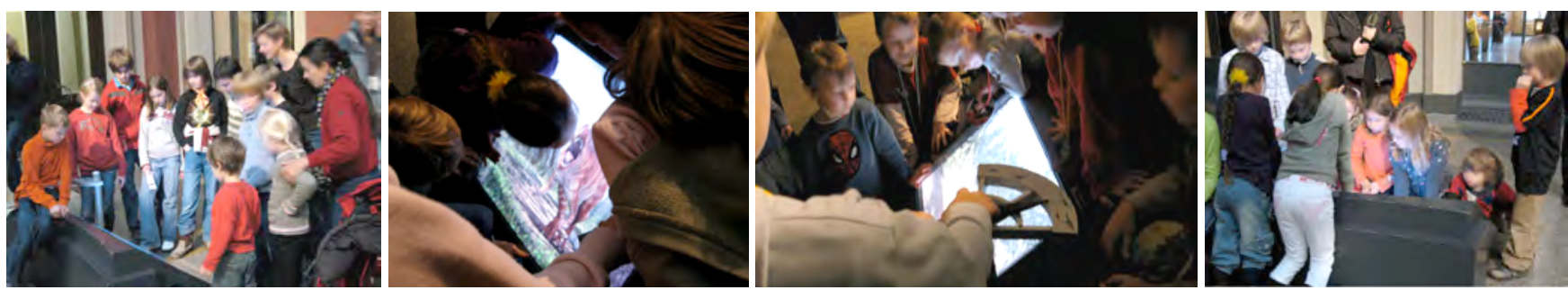

Figure 4. Groups huddling around the screen, with a shared focus of attention, chatting, and acting towards the animated films 
The screens can be described as providing a very social and shared experience, supporting co-experience [3]. They were usually surrounded by a crowd (6 to 15 people) with several subgroups. Here, people were not just waiting, but actively watching and commenting, scaffolding and negotiating use of the lever mechanism. Conversations emerged not only within, but also across groups. In particular, adults were able to conduct educational conversations with children and to direct their attention, e.g., pointing out which skeleton in the hall related to a film. This relationship was often turned around with the children knowing a lot about dinosaurs [18]. The Tele-Jurascope deprived children of this opportunity to take the role of a knowledgeable expert.

This difference in conversation patterns shows from the transcripts. Long periods of silence characterize interactions with the Tele-Jurascopes, whereas at the screens there were usually several parallel conversations. Scenes such as a carnivore hunting small bird-like creatures that evoked comments at the screen were viewed in utter silence at the telescopes. The ability to share is likely to underlie another observation. Caregivers tended to move children on from the telescopes, to 'let others have a go' much quicker than at the screens, where they often watched each film twice. The telescopes acted as a restricted resource, making visitors feel obliged to make way for others.

The following vignette shows animated talk from several children. Two boys (Boyl shows off his expert knowledge) appear to belong together and are joined in their conversation by other children, while a fourth child, invisible in the video, manipulates the lever.

(3) The Dinosaur on-screen 'skins down' to a skeleton. Boy1 points into the room: 'That's this one' (a skeleton on display). Boy2: 'Oh!' The screen moves to show another dinosaur. As the inner organs appear, Boy2 exclaims in disgust 'Uah'. Boy1 says: 'Guess how much it weights. - That was the heaviest dinosaur that ever lived.' showing off his expert knowledge. A new animation starts. Boy2: 'Hey, I don't know that one'. It is a peaceful herbivore, munching grass. As the dinosaur looks interested into the screen and makes cow-like noises, a third child points at the screen: 'Shut up'. A younger child picks this up: 'Shut your gob, you potato!' Now several children with playful insults tell the animal to be quiet, pointing at the screen.

\section{Indexing Into the Environment}

For museums that have authentic objects in the centre of experience [16], the question is how to augment exhibits so that visitors can focus on them $[7,14,16]$ and how to encourage them to make connections [19]. The Jurascopes are designed to link between the original skeletons on
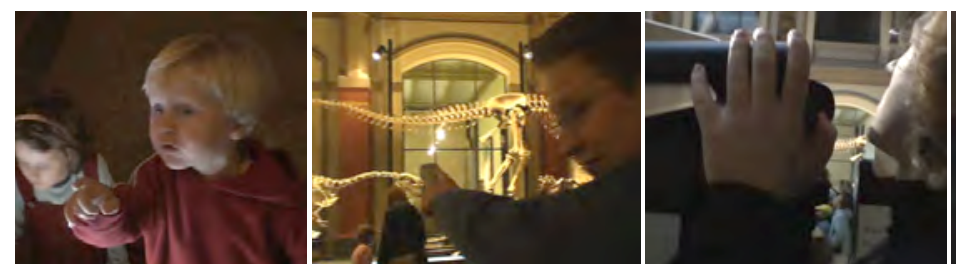

Figure 5. (a, b) Pointing and looking back and forth at screens. (c, d) Glancing over Tele-Jurascope

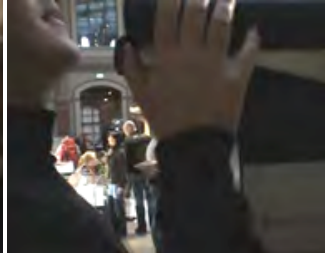

display and animated movies of dinosaurs familiar from TV. The installation is located quite unobtrusively in the corners of the hall, having a 'serving function' to exhibits. It is carefully embedded in the environment, making visitors look out towards the skeletons in direct line of sight. The animations are thus contextualized through a meaningful spatial setup; they refer and index to the skeletons in the same room. The gradual build-up of animations starting with a naked skeleton further supports visitors in understanding these references.

From a design standpoint, the provision of indexes can be considered a quality of an interface. From an ethnographic viewpoint, it is people who do the indexing, looking back and forth, making connections by pointing or verbally referring to objects, and their overt behavior makes this activity visible to the observer. For the researcher, behavioral patterns of 'indexing' indicate whether the installation fulfils its aims and provide clues as to what aspects of the interface engender it. The video data yields numerous examples of children and adults indexing to the skeletons (verbal or non-verbal). Parents point at the screen and then up into the exhibition hall look, now this animal comes. It is over there, the one with the long tail'. The following transcript from one of the shadowed families gives an example of how very young children already understand the relationship between skeletons and films, and how parents emphasize and reinforce the connection.

(4) Father, mother, 3-year-old son Bob and a 4-year-old daughter watch a big dinosaur on the screen. As the animation finishes, Bob reaches up, pointing at the tallest skeleton in the hall: 'The GIANT DINOsaur'! The father suggests walking to the other screen and they start walking through the hall. The daughter runs in front. Walking past the skeletons, the father tells his son: 'And these are the skeletons to it. They were soooo big!' The daughter repeats: 'They were so big'. (...) After watching the other screen, they walk back and pass the skeletons again. The father reaches out to Bob: 'Look, that's the dinosaurs from the film.' He points straight up at a large skeleton, looks up, then down at Bob. As Bob looks at the skeleton he lowers his arm: 'Look, Bob, the big one? That's the one (points at its head) that yelled at us (bends down) see, this one roared at us' (points up, now kneeling next to Bob). Bob agrees: 'Yeah, that is...' and the father expands: 'it was eating a saurier's leg. And this small one (points at another skeleton) was being chased (points to a third skeleton) this was a predator, He chased the other one.' Later they are looking at the animations again. An animation starts. Bob stands up and points into space: 'There it comes again: THE BIG one'

This vignette features a whole series of cross-references, started by the son pointing from the screen to the skeleton. The father emphasizes the size of the dinosaurs as they are right next to the skeleton, which towers over them. On both ways past the skeletons he 'indexes' back to the animation, the second time recalling details of the film. Seeing the animation again, the son demonstrates that he remembers this is the huge 


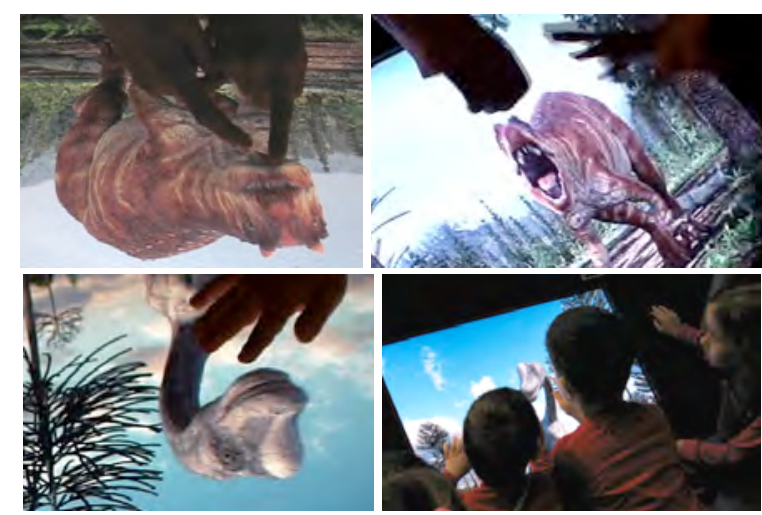

Figure 6. Acting towards the screen. $(\mathrm{a}, \mathrm{b})$ Pointing at Allosaurus' mouth, two boys repeat: 'bite me, bite me'. Two children knock at the screen as Allosaurus roars. (c, d) The friendly and curious treenibbling dinosaurs evoked tapping and stroking the screen.

skeleton that they looked up at. Making these references is supported through the uninterrupted visual flow on the walk from the screens past the skeletons and back; there are no visual/spatial barriers that to break up the experience.

Indexing also occurred at the Tele-Jurascopes. Because there was less talk here, verbal and gestural references were less frequent than at the screens. Still, there was evidence from subtle bodily behaviors. In the following vignette a visitor repeatedly glances over the viewer towards the skeletons before turning it, using the real exhibition hall for reference and overview of choices. These glances also happened at the screens, both by adults and children.

(5) John takes a position at the telescope. He briefly glances back at his friends, then watches in silence as the animation unfolds. He quickly goes on his toes and glances over the viewer into the great hall. Then he watches another 10 seconds in silence. Again, he has a look over the viewer towards the skeletons, and then moves the Jurascope to the right. A friend asks: 'Do you have the one on the far right now'? John answers: 'Mhhh, the left one. From these (gestures to skeletons) the two, you see them skipping around'.

\section{Interactions Around the System}

Museum researchers increasingly adopt a skeptical position on the role of interactive installations [1, 5, 22]. Some even argue that interactivity is a property of users, not of systems, and point out that many interactives impoverish social interaction and limit co-participation [5, 10]. In particular, it is not necessarily the installations with the most interactivity (or content) that make good and engaging exhibits $[1,10,14,21]$. The Jurascope installation as such is not very interactive; it allows choosing and watching an animated movie from a few alternatives. In comparison, the multi-touch table created by the same design company offers a lot of content and various interaction options. Yet there was little engagement with the content, any discussions mostly concerning how to interact [11]. At the Tele-Jurascopes, co-participation opportunities [10] were limited. People in the queue tended to talk about things they had previously seen or told anecdotes, such as how the museum looked like in the communist era. These were longer and more coherent conversations than those around the screen, but mostly served the function of filling time.

Observation revealed how engagement at the screens manifested itself in a richness of interactions not only with the system, but, more importantly, between participants and around the system (cf. [12, 9]). In contrast to findings reported elsewhere [19], companions as well as strangers took part in social interactions. These usually explicitly or implicitly referred to the system or its contents. A variety of kinds of discussion and talk were observed. Visitors commented on animations, narrated or enacted them. Adults engaged in educational talk with children and would often moderate children's behavior, direct their attention, or suggest how to use the lever. Children were eager to demonstrate their knowledge by using species names and quickly categorizing animals (cf. [18]).

The films were often animated and enacted verbally, using onomatopoeic expressions ('Yum' or 'hum' for biting). Children often playfully pretended to interact with the dinosaurs (see figure 6), touching the screen, shouting back at them or telling them to 'run away, quickly' from approaching predators. They especially liked to challenge Allosaurus, hitting it, putting their head close, and yelling 'eat me'. Adults and children tended to illustrate and emotionalize the scenes through comments. E.g. a child addresses Kentrosaurus, which has large spikes on its spine, as it starts to fend off another dinosaur: 'Yeah, now you beat your tail around'. In the following vignette, the children express pity for the previous owner of the leg that Allosaurus eats. Towards the end Child1 puts the group into the scene, suggesting 'and now it eats us up'.

(6) The Allosaurus animation starts. Child 3 recognizes it and comments: 'Oh, cool, wicked'. The dinosaur starts biting into a piece of meat (a thigh) on the ground. Child 3 now expresses pity for the dead animal: 'the poor one'. A man explains: 'it feeds' and Child1 picks up the theme of pity: 'poor little dino'. Allosaurus seems to discover the observers, approaches them and roars. Child1 asks: 'Is it angry'? Child 2 says: 'the small one'? Child1 continues: 'and now it eats us up'. Child3 assures them: 'No'

Sometimes adults reassured fearful children 'Look, they don't do anything to each other'. Parents often pointed out aspects of the animation to children ('watch, now it is feeding from a tree'). This was supported by size and visibility of the display and was rarely observed at the TeleJurascopes. With younger children, adults tended to narrate, repeat, and emotionalize the story, and to direct attention: 'now they come again - now they cackle again' (after chase scene), or: 'lets see what this one eats'. Educational conversations were frequent, adults using the opportunity to add context, explain, or abstract: 'it defends its territory'. A mother comments on Allosaurus: 'Hoo, that one has sharp teeth. Good it has been dead for a long time!' reminding the child that dinosaurs are extinct. When his young daughter remarks about Brachiosaurus that 'the other dinosaurs don't have such a long neck' a father explains its function: 'This one can eat the leaves even from the highest trees.' 
Adult caregivers as well as other children instructed smaller children how to use the lever. A father tells his son 'let go, otherwise the movie doesn't come' and a girl instructs another child: 'Take your hand off - there, let go, let it run'. There were various situations of strangers talking to each other. Unrelated adults attempted to calm down excited or fearful children, and instructed them on how to use the lever. Often children informed strangers that 'this is a nasty one'. Involvement of strangers was specific to the screens. It did not occur at the Tele-Jurascopes at the dynamic legends (horizontal information panels), or the interactive table (see [11]). In the following vignette several things can be noticed. There is inter-group conversation, a young boy replying to an unrelated adult, showing off his knowledge about the animations and correcting the adult's statement, and animating narration that emotionalizes the scene.

(7) About 12 people surround the screen, with several parent-child groupings and some lone children. A mother and her small daughter have been watching for a while. Kentrosaurus is selected. Mother: 'That's the one with the long spikes'. A young boy tells the crowd: 'Yeah, I know what is coming, but I won't tell you'. Allosaurus, a giant hunter-carnivore approaches and roars threatening. The boy shouts: 'he wants to eat you, ha!' The Kentrosaurus turns around, roars and swings its muscular, spiked tail. The mother explains to her child: 'He threatens him, so he runs away'. The boy corrects her: 'No, not yet! First - Now - now it runs away'. The Allosaurus leaves.

The Lever as a Tangible Means of Externalizing Control Control and selecting animations at the Tele-Jurascopes and at the screens is performed through physical manipulation. For the Jurascopes this feels akin to turning a telescope at a touristic lookout point. For the screens the mapping is less literal. For this reason the lever is large and very visible, with a display of the possible choices on its dashboard (see figures 4 and 8d). Furthermore, the lever is located at childlevel, inviting children to use it. The simplicity of the lever worked well in terms of immediate apprehendability [1], and visitors quickly figured out what to do. At the screens,
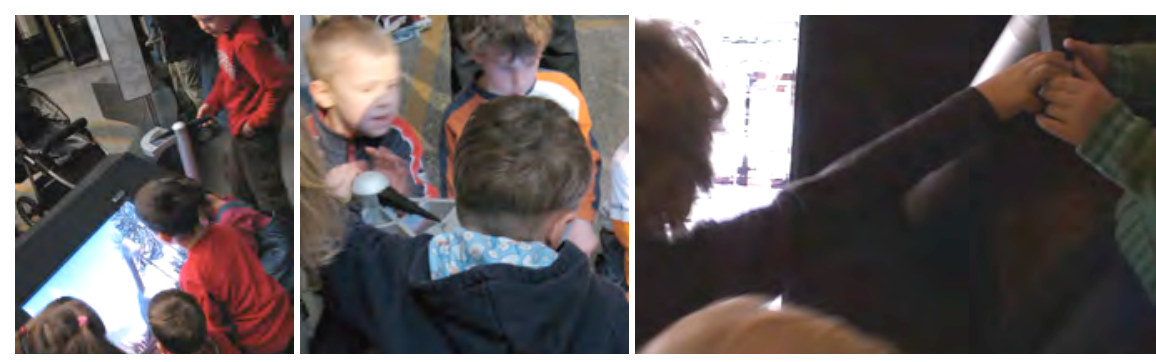

Figure 7(a) Steering for others. $(b+c)$ Children reaching over and struggling over control.

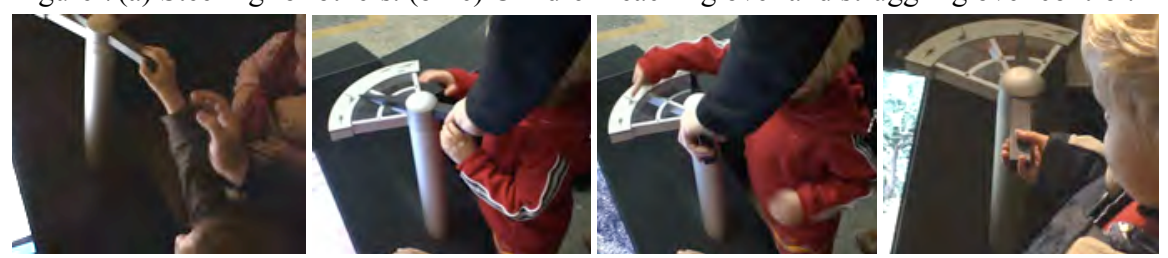

Figure 8(a) Father guiding daughter's hand. $(b+c)$ : Mother and son jointly move the lever. Mother points at lever: 'Look, when you put the needle here then the long one comes'. The son points at the icon for the long dinosaur. (d) A concentrated expert user children were predominantly in control, occasionally facilitated and scaffolded by adults or older children. Adults seemed to interpret the screens as being aimed primarily at children due to the physical setup and the height of the lever, and thus kept in the background, forming a second circle around the children.

At first, this setup appears rather limited from a tangible interaction viewpoint. The lever only allows one person to be active, and the only feasible action is turning it to choose one from four dinosaurs. Interpreted as a shareable interface [13], there is only one access point for manipulation. Nevertheless, the design supports sharing. Whereas control is centralized, the content is easily shared since size and physical setup of the screen accommodate a large group of viewers. In this case, distributing control would lead to conflict and interference, there being only one screen. Moreover, observation and interaction analysis of video data reveal the lever's role in negotiating control and handling conflict. The lever is a large access point and thus it is very visible who currently is in control. This in turn means that others can easily monitor their actions. The lever through its physical size and form thus externalizes control.

The user of the lever is a mediator and proxy-user for the other visitors, who negotiate which dinosaur to select next. Negotiation about what to see next tended to be verbal and surprisingly peaceful, despite the number and young age of children. Physical struggles over control (figure $7 \mathrm{~b}+\mathrm{c}$ ) were usually resolved by bystanders making suggestions and telling children to calm down. The data contains many examples of verbal negotiation within and across visitor groups, and of bystanders scaffolding use of the lever, giving instructions on how to manipulate it.

(8) Two boys that stand next to the lever discuss which dinosaur to select next and repeatedly move the lever around, switching between animations. The father of a shadowed family addresses them: 'Main thing is we pick one, OK?'

(9) A family with small children joins people at the screen. A short while later, 2 other children compete for control of the lever. One is next to the lever and holds on to it, while a smaller boy reaches over to move it. The mother talks to her child: 'look, there's movies. If you leave it at one side we can watch films. Leave it on one side?', now addressing the child at the lever. The child at the lever says: 'to the Diplo' starting to negotiate a choice with the other children. The small boy who previously interfered moves the lever to the right, following the request. The animation starts, and he asks, pointing at the dinosaur that is now chosen: 'this one?'

Children often learnt from watching others how to use the lever and, when taking over, immediately manipulated it correctly. The lever's tangibility and visibility enabled scaffolding children in 
ways not feasible at the Tele-Jurascopes, where parents would hold up children to the viewer, but were unable to monitor what they could see. The following vignette shows an example of a father letting his 3-year-old daughter feel in control of the lever, but delicately guiding her movement.

(10) Father to daughter: 'Now we can watch the others'. He reaches for the lever, kneeling behind his daughter. Then he hesitates and pulls back his hand: 'move here' and now merely points at the lever. The daughter reaches out for the lever. Her father keeps his hand in a bowl shape around his daughter's hand, stabilizing her and discouraging her from jerking her hand. She grabs the lever and he slightly holds her hand. Father: 'Yes, exactly - let go'. She releases her hand and the animation starts. Daughter: 'Dondi'. Father: 'great, what?' Daughter: 'such a long tail!'

The key to using the lever is pointing it correctly and keeping it still while the animation runs. Over time some children clearly developed expertise. They were quick in selecting a dinosaur and, knowing the films, would move the lever on when the scene reached its end, not waiting for the dinosaur to be put back into the museum. Children at the lever gave a very focused appearance, seemingly aware of the importance of their role (figure 7a and 8d). In video analysis, it became apparent that some children tended to keep their hand on the lever at all times, even though this risked moving it and interrupting the film. This seemed to have the function of retaining control.

\section{Physical Arrangement Around the Screen}

Extended observation and analysis of the photo documentary revealed a consistent pattern of how people arranged themselves around the installations. A physicalspatial setup is not just a given, but is also created by the people partaking. The physical embedding of the system thus includes the people around it. This arrangement evolves not arbitrarily, but at least partly in response to environmental constraints and affordances, influenced by shape, structure and behavior of the system (Embodied Facilitation [12]). To ensure that an installation has the potential to engage many visitors simultaneously, interaction design needs to understand how such patterns evolve and how to design for them.

At the Tele-Jurascopes, orderly queues built up regularly. Groups aimed to reduce waiting time by lining up in adjacent queues. People at the viewer tended to be alone, sometime with a partner or caregiver close-by, or adults held children up to the viewer. Around the screen the dominant pattern was that of a 3D half-circle in ascending height, comparable to the inside of a bowl (see figure 9). Such a semi-circular arrangement has also been observed by vom Lehn et al [19], but without the 3D aspect.

The screen is installed at a $30^{\circ}$ angle, embedded in a sturdy stone casing that rises out of the floor. The pattern that continued to repeat itself was that of small children kneeling in front of the screen, other children standing behind them, bigger children in the next row, and adults in the back at some distance. The angle of the screen and its

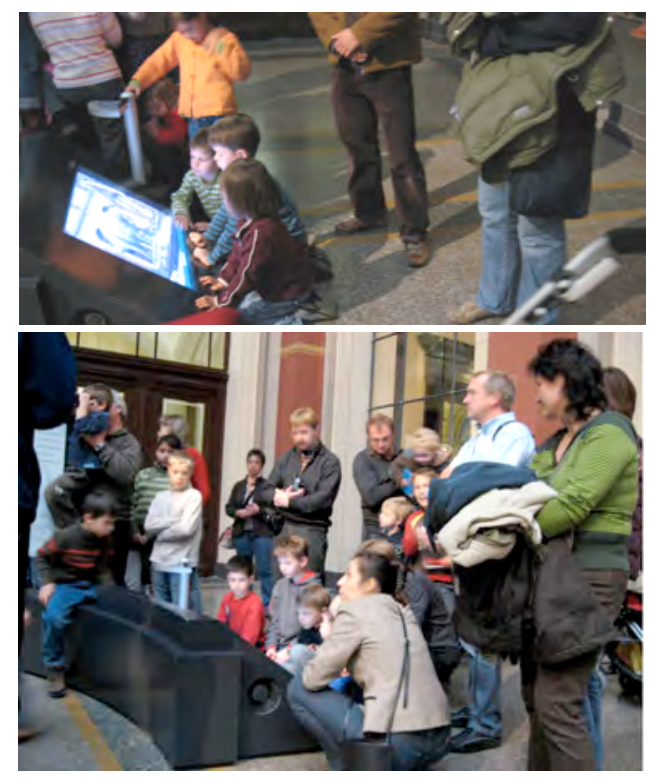

Figure 9. How larger groups of visitors arranged themselves around the screen: small children at the front, adults in a halfcircle in $2^{\text {nd }}$ or $3 \mathrm{~d}$ row and older children in between.

low position allowed everybody to glance over the heads of those in front of them. During busy times, some children or adults would peer in from the side or stand on the backside of the screen, watching everything upside down. Some people sat sideways on the stone casing, glancing in. The photo documentary showed that typically six to 14 people, and up to 20 , gathered round the screen. The shape factor of the display thus maximizes the number of people able to view, while accommodating children, who normally often end up not seeing anything but people's legs. The crowd in turn tends to draw further visitors, curious about the attraction (a honeypot effect [6, 13]). The lever was primarily used by children aged from three to eight. Again, a pattern emerged of adults and older children leaving control to younger children. It seems the height of the lever particularly accommodates children of this age, as adults would have to bend down and smaller children to reach up.

Besides the physical design of the installation, social expectations and behavior rules for museums take effect here. Adults clearly perceived the screen to be primarily for children and tried to retain visibility for small people. Older children automatically did the same, going into the $2^{\text {nd }}$ or $3^{\text {rd }}$ row. There was almost no explicit reference as to where to position oneself, and adults rarely told children where to stand. Despite remaining in the back-row, some adults without children also spent time watching, indicating the installation served multiple visitor categories.

\section{CONCLUSION}

Whereas at the start of the research it had seemed as if the Tele-Jurascope would be the most interesting installation, it soon turned out that a much richer ecology of interaction developed around the screens. In comparing the kinds of experience and interactions, we need to understand the 
relationships with the physical design of the installations. Here, a tradeoff between immersion and sociality of the user experience emerged.

This study contributes to an improved understanding of sharability and co-experience. It highlights the important role of something as simple as a (well-designed) lever. This mechanism works well to select between a small number of choices. The lever only provides a single access point, but its tangible nature supports shared control due to its high visibility and externalization of control, turning its user into a proxy for the group. It made children feel empowered, and proved to be easy to use for all ages. This exemplifies how tangibility can be important even if only parts of the system are tangible. The study furthermore shows that with tangible and embedded interaction not just the interface perse is to be considered, but it is the overall physical set-up and arrangement (cf [12]) that create rich interactions around the system. It is the careful placement of the screen in relation to the museum exhibits, at a low level and angled, along with the tangibility of the lever that enable groups of strangers to mutually orient to the screen and to communicate, negotiate and enjoy themselves, and to create connections between the films and real exhibits.

The findings also inspire us to think of installations as comprising the audience, having us think about space architecturally - what spatial arrangements does the system produce and how does this affect further approaching visitors. Moreover, a new issue that has emerged is how to design for indexicality. This means more than just integrating systems into a context; it is about purposely enabling comparisons and references in both directions. In this case, indexes were implicit, and it was up to users to do the actual indexing, leaving agency to them.

Acknowledgements: Thanks to the Museum für Naturkunde Berlin for granting access, the staff at $\mathrm{ART}+\mathrm{COM}$ for background discussions, all volunteers in the shadowed groups, and J.H. Israel for his hospitality. The study was funded by German DFG fellowship grant Ho3901/1-1.

\section{REFERENCES}

1. Allen, S. Designs for learning: Studying science museum exhibits that do more than entertain. Science Education Vol 88(S1) 2004, pp. S17-S33

2. ART+COM. http://www.artcom.de/index.php?option= com_acprojects\&page $=6 \& \mathrm{id}=58 \&$ Itemid $=144 \&$ details $=$ $0 \&$ lang=en (read July 2009) and http://www.artcom.de/index.php?option=com_acproject s\&page $=6 \&$ id $=59$ \&Itemid $=144 \&$ details $=0$ \&lang $=$ en

3. Battarbee, K., Defining co-experience. Proc. of DPPI 2003, ACM. $109-113$.

4. Blomberg, J. et al. Ethnographic field methods and their relation to design. In: Schuler, Namioka (eds.) Participatory Design. Lawrence Erlbaum 1993, 123-155

5. Bradburne. J. Is interactivity different for fine art as opposed to design? Proc. of Interactive Learning in Museums of Art. V\&A Museum 2002.
6. Brignull, H., Rogers, Y. Enticing people to interact with large public displays in public spaces. Proc. of INTERACT 2003, pp. 17-24

7. Ciolfi, L.; Bannon, L. Learning from museum visits: Shaping design sensitivities. Technical Report IDCUniversity of Limerick (2002).

8. Dourish, P. Where the action is. The foundations of embodied interaction. MIT Press (2001)

9. Fernaeus, Y., Tholander, J., Jonsson, M. Towards a new set of ideals: consequences of the practice turn in tangible interaction. Proc. of TEI 2008. ACM. 223-230

10. Heath, C., vom Lehn, D. Misconstruing interactivity. Proc. of Interactive Learning in Museums of Art. V\&A Museum 2002.

11.Hornecker, E. I don't understand it either, but it is cool" Visitor Interactions with a Multi-Touch Table in a Museum. Proc. of IEEE Tabletop 2008. 121-128

12. Hornecker, E.; Buur, J. Getting a grip on tangible interaction: A framework on physical space and social interaction. Proc. of CHI 2007, ACM. 437-446

13. Hornecker, E., Marshall, P., Rogers, Y. Entry and Access - How shareability comes about. Proc. of DPPI 2007. ACM, 328-342

14. Hornecker, E., Stifter, M. Learning from interactive museum installations about interaction design for public settings. Proc. of OzCHI 2006. ACM, pp. 135-142

15. Jordan, B., Henderson, A. Interaction analysis: Foundations and practice. Journal of the Learning Sciences, vol. 4, no.1, 1995, pp. 39-103.

16. Kelly, L., Savage, G., Griffin, J., Tonkin, S. Knowledge quest: Australian families visit museums. Australian Museum and National Museum of Australia 2004

17. Museum für Naturkunde Berlin http://www.museum.huberlin.de/index_english.html

18. Palmquist, S.D., Crowley, K. Studying dinosaur learning on an island of expertise. In Goldman, Pea, Barron \& Derry (eds). Video research in the learning sciences. Mahwah, NJ: Erlbaum. 2007

19. vom Lehn, D., J. Hindmarsh, P. Luff, C. Heath. Engaging Constable: Revealing art with new technology. Proc. of CHI 2007. ACM. 1485-1494

20. Wakkary, R., Hatala, M. Situated play in a tangible interface and adaptive audio museum guide. Personal and Ubiquitous Computing, \#3(11), 2007. 171-191

21. Wakkary, R., Hatala, M., Muise, K., Tanenbaum, K., Budd J., Kurio: A Museum Guide for Families. Proc. of TEI 2009, ACM. 215-222

22. Whitcomb, A. Interactivity: Thinking beyond. In: Macdonald (ed.): Companion to Museum Studies. Blackwell Publishing 2006. 333-361 